\title{
Diversity of innovative strategy as a source of technological performance $^{1}$
}

\author{
Patrick LLERENA, Vanessa OLTRA
}

BETA

University Louis Pasteur

61, Avenue de la Forêt Noire

67070 STRASBO URG CEDEX

Tel: (33) 390414165

e-mail: pllerena@ cournot.u-strasbg.fr

\author{
IFREDE-E3i \\ University Montesquieu Bordeaux IV \\ Avenue Léon Duguit \\ 33608 PESSAC \\ Tel: (33) 556848640 \\ e-mail: oltra@montesquieu.u-bordeaux.fr
}

to be published in "Economics Dynamics and Structural Change", forthcomming

\begin{abstract}
This paper explores the impact of diversity of innovative strategy of firms upon the industrial dynamics through a micro-simulation model. We consider two types of firms each one being characterised by a specific innovative strategy. Basically we assume that some cumulative firms adopt an internal learning by searching strategy, while non-cumulative firms adopt an external learning strategy aiming at absorbing external sources of knowledge. The results show that the co-existence of these two types of firms leads to an oligopolistic structure characterised by asymmetries in the size of firms and high technological performances. Thus the diversity of innovative strategy generates a diversity in firms market shares and is a source of dynamic efficiency in the long run.
\end{abstract}

\section{Keywords}

Industrial dynamics, innovation, diversity, learning.

\section{JEL Code}

L1, C63

\footnotetext{
${ }^{1}$ The support of CNRS research programme "Les ejiex éconmiques del'innovation" is gratefully acknowledged. The first draft of this article was presented at the 7th Conference of the International J.A. Schumpeter Society, Vienna, Austria, June 1998. This final version was presented at the AFSE Conference, "Economedel'inmovation", Nice-Sophia Antipolis, France, May 1999.
} 


\title{
Diversity of innovative strategy as a source of technological performance
}

\author{
Patrick LLERENA, Vanessa OLTRA
}

\section{Introduction}

Most empirical studies on industry evolution emphasise interindustry variations in terms of performances and innovative behaviour of firms (Cohen and Levin, 1989; Cohen, 1995; Patel and Pavitt, 1995; D osi, Malerba, Marsili and Orsenigo, 1997). These studies generally focus on the size of firms which is pointed out as an explanatory variable of the variations in technological performances. Along the same line of inquiry, a substantial body of descriptive evidence has been accumulated on how the nature and effects of demand, opportunity and appropriability conditions differ across industry. Malerba and Orsenigo $(1996,1997)$ study the role of the characteristics of the technological environment upon industry evolution by using the Schumpeterian concept of technological regime. The basic argument is that the nature of knowledge, the cumulativeness of innovation, as well as opportunity and appropriability conditions, lead to different patterns of innovative activities which strongly influence the evolution of technology and industrial structure. The characteristics of the technological environment, which define the technological regime, are put forward as an explanation for interindustry variations.

One neglected issue in the empirical literature is the role of intraindustrydifferences among firms in innovative strategy and technological performances. The theoretical literature provides some guidance in identifying the sources of these interfirms variations in innovative activity. The evolutionary theory of technological change underlines the specific and cumulative character of innovative activities of firms. The paradigmatic representation of technological change suggests that there are several local innovation processes going on at the same time in the boundaries delimited by the paradigm (D osi, 1988a). It leads to a diversity of innovations, more precisely to a diversity of technological knowledge and competencies developed by firms.

The work of Nelson and Winter (1982) puts forward that, in a world of bounded rationality and radical uncertainty, firms accumulate technological competencies and knowledge which may strongly differ according to their experiences and their "innovative draws". In this framework, interfirms variations mainly result from the past history of success and failure of firms in their R\&D process. Although the model of Nelson and Winter presents some restrictions, it sheds some light on the role of heterogeneity of firms in the evolution of the structure of a single industry.

Related to this topic of diversity, Malerba (1992) proposes a conceptualisation of learning which can be summarised in two hypotheses. First, firms learn in a variety of different ways that may be linked to different sources of knowledge. Secondly these various learning processes generate a range of technological trajectories.

The purpose of the model presented in this paper is to propose a framework which enables us to analyse more deeply the role of these intefims technological variations within industry. We propose to focus on the diversity of learning and innovative strategy of firms. We investigate this issue not only by considering technological diversity as an outcome of the innovation and selection processes, but also by taking into account the diversity of firms' innovative strategy. This latter dimension corresponds to an intentional form of diversity that is linked to the strategic decisions of a population of firms producing 
an homogeneous good. Our purpose is to explore through simulation the interplay between this diversity of innovative strategy and the resulting technological diversity which characterises the industry in the long run.

First we present the main features of the diversity of innovation and learning process of firms. In the second section we present our model of industrial dynamics, and finally we analyse the results of simulation.

\section{Diversity of leaming and innovative strategy of firms}

The concept of diversity and related notions such as heterogeneity and variety are integrated in the economic literature with different meanings according to the theoretical background. In the neoclassical framework, the diversity of factor endowments is the main source of comparative advantages: differences in opportunity costs between economic agents, regions and countries lead to comparative advantages. This is the main reason for (and explanation of) the division of labour and trade and thus, in a way, the starting point of the whole theoretical construction of the neoclassical exchange economy.

The growing diversity of products and services that we use in our everyday life and in productive processes is, as Saviotti (1991) points out, one of the most important aspects of economic development. While the variety of products and services increases, some existing products and processes disappear. The balance between the emergence of new and different products and services and the disappearance of existing ones determines the net static variety of the economic system at a given point in time. Strategies of product differentiation as well as process and product innovations are laying behind these phenomena.

More recent developments have emphasised other sources of diversity. Many theoretical and empirical works reveal the limits of a concept of diversity only linked to the variety of products or endowments. In particular it seems important to focus more on the diversity of behaviours and strategies. This type of diversity has been at the centre of the literature in industrial organisation of the 1950s and the 1960s. More recently the priority has been given to innovative strategy and technological performances of firms. The purpose mainly consists in explaining the heterogeneity of innovative activities among firms. On this topic, empirical studies focus on industry-level factors determining innovative activity of firms ${ }^{2}$.

In comparison to our understanding of the influence of industry-level variables, our understanding of that of firm-level is more primitive. There is however a need to identify and analyse the differences among the firms of a given industry in terms of technological competencies and innovative capabilities. The proposition that within industry firms may differ in their innovative activities and technological performances suggests that the effects of industry-level factors may differ across firms. Our contribution focuses on this intra-industry level of diversity.

\section{The sources of intra-industry diversity}

In evolutionary approaches industrial dynamics is considered to be a process of economic change driven by the diversity of economic behaviours. The competitive issue is explored through the coexistence of firms with different behaviours and the pattern of their relative growth and survival. In this framework the question is how a selection environment translates this diversity of behaviours into patterns of economic change, in particular into diversity in growth rates and market shares of firms. Focusing on the selection process, Metcalfe (1992) shows that changes take place because of the variety of behaviours coexisting in the selection environment and that the rate of change is directly related to the consequent diversity in the rate of growth of competing firms.

Productivity differences among firms in the same industry reflect this diversity of firms' behaviours and performances. Nelson (1996) emphasises that cross-firms variation in productivity is mainly due to

\footnotetext{
${ }^{2}$ For a survey on that question, see for example Cohen (1995).
} 
internal organisational aspects and to differences in the process of technological advance of firms. In this perspective, Dosi (1988b) highlights that the process of technological change is cumulative and specific to firms: "...techndogical progess promets through thededopment and explatation of both publickements of knowkeege, shared by all adars invdved in a cetain adivity, and private, local, partly taat, fimsspeific, amilative foms of knowleelge' (D osi, 1988b, p.226).

These arguments leads us to focus on the searching and learning process which drives innovative activities of firms. In a given environment, firms may learn and innovate in a variety of different ways because of their experiences, knowledge base and competencies. Malerba (1992) provides a taxonomy of learning, distinguishing between the learning that emerges from experiences in production or use, the learning resulting from the exploitation of external sources of knowledge and the learning that is linked to internal research and problem solving. These different sorts of learning affect the kind of innovative activities pursued by firms: "Fims then beeme haracteised by different lexds and types of 'knowkedge capital' acoumlated through time' (Malerba, 1992, p.847). As a matter of fact different local innovation processes go on at the same time creating technological trajectories specific to firms. It is thus possible to describe technical change as a process of change that builds on diversity and in the meantime creates diversity: "diversity drives evolution and evolution generates diversity" (Cohendet and Llerena, 1997, p.227). The market place works then as selection devices and induces particular industrial dynamics which can be capture in terms of market structure and productivity differentials.

This dimension of diversity is also linked to different strategic choices of firms. For instance, in the case of the pharmaceutical industry, Grabowski and Vernon (1987) point out that firms exhibit different types of $R \& D$ strategic behaviours such as pioneering $R \& D$, which involves the development of radically new products, imitative $R \& D$ and generic competition. $O n$ this topic of the diversity of innovative strategy of firms, the pharmaceutical industry can serve as an archetypical example. This industry is an example of a "science-based" industry in which innovation is the fundamental source of competitiveness among firms. Bottazzi et al. (2000) shows that the evolution of this industry is characterised by a significant heterogeneity in terms of firms strategic orientations and innovative capabilities: "...in most singemarkes and in theindustry as a whdeonedoseres the persistent coexistence of two basic types of fims, mapping into distint techndogical comptenies and competitive strategies..the first group dosty comesponding to the cre, undatakes what is sometimes called pioneering $R \& D$...thesecond group undatakes pimanily imitativeR\&D andgeneratesincremental innovations" (Bottazzi et al., 2000, p. 6).

An interesting question emerging from these considerations concerns the impact of this diversity in firms innovative strategy upon the industrial dynamics of sectors.

\subsection{The impact of diversity upon industrial dynamics}

Various models of industrial dynamics study the diversity of firms behaviours in R\&D and innovative strategy. A first category of models shows that technological diversity is a result of the innovation process. The work of Iwai (1984) proposes an interesting element of explanation of the emergence and persistence of technological diversity. In his model, Iwai introduces sequentially innovation and imitation in order to study their impact upon the technological configuration of the industry. In a static context without technological change, Iwai (1984) shows that, in presence of several technologies, the market tends to select the best technology. Iwai compares this selection process to Darwinian selection in the sense of "selection of the best". In a second step, Iwai (1984) introduces imitation which enables all the firms to survive thanks to the imitation of the best technology. Technological diversity appears as soon as innovation is taken into account. Iwai (1984) shows that selection and imitation tend to decrease diversity, while innovation, by introducing new technologies, enhances diversity. The results of the model show that these three interacting forces - selection, innovation and imitation - leads to the co-existence of various technologies in the industry in the long run. This model is a good illustration of the basic principle of evolutionary theory according to which industrial dynamics is driven by the mechanisms of creation and selection of diversity. In the Nelson and Winter (1982) tradition, Jonard and Yildizoglu (1998) obtain a similar result by introducing localised learning and increasing returns to 
adoption. In this paper, the authors study the impact of heterogeneous behaviours on the emergence of technological diversity.

A second category of model insists more on the fact that the diversity of behaviours can be considered as a necessary condition for the process of technological change. For instance, Silverberg, Dosi and Orsenigo (1988) show that the diversity of behaviours is necessary for the adoption of a new technology characterised by uncertain returns. In the same vein, Chiaromonte and Dosi (1992) show that the diversity of behaviours and competencies has a positive effect on the rate of innovation. The results of their simulations point out that the rate of innovation and the aggregate outcome are lower when firms exhibit similar microeconomic characteristics. More recently Ballot and Taymaz (1997) consider a more complex situation including diversity of decision rules in physical investment, training and R\&D. They are able to show that diversity of rules is self-sustained and that in spite of learning there is no tendency towards uniformity. Their results exhibit a fairly stable steady state of diversity and show the importance of variety for macroeconomic performances. These various contributions indicate that the diversity of firms' expectations, behaviours and learning processes tends to foster technological change and economic performance.

The conclusion of these various models is that diversity is in the meantime a result and a condition of technological change. The model presented in the following section falls within the same perspective with particular emphasis on the role of the heterogeneity of firms' learning and innovation strategy.

\section{The model of industrial dynamics}

The influence of diversity upon industrial dynamics is studied through a micro-simulation model which depicts the evolution of firms' market share and technology. The purpose is to analyse the emergent properties of the industrial dynamics which result from the interactions between heterogeneous firms.

The basic structure of the model is based on Oltra (1997a, 1997b). We consider an industry composed of $\mathrm{n}$ firms assumed to produce the same homogeneous good with a unique production factor which is capital. This industry faces a downward sloping demand curve with price-elasticity equal to one. Capital is numeraire so that its unit cost is supposed equal to one. In the Nelson and Winter (1982) tradition, each firm is characterised by its capital stock and its productivity level. Productivity (output per unit capital) represents the technology of each firm which can be improved through innovation. This last assumption means that technological change is not enbodied in capital or equipment. In such a context, innovations lead to improvements in production techniques which are modelled as increases in capital productivity. This also means that the process of technological change is driven by incremental process innovations which lead to a more efficient utilisation of capital.

\section{- The basic structure of the model}

At the beginning of period the state of the industry is given by:

$$
\begin{aligned}
& K_{t}=\left(K_{1 t} \ldots K_{i t} \ldots K_{t t}\right) \\
& A_{t}=\left(A_{1 t} \ldots A_{i t} \ldots A_{t t}\right)
\end{aligned}
$$

where $K_{i t}$ is the capital stock and $A_{i t}$ is the capital productivity of firm $i$ at period $t$

The output of firm i at period $t\left(Q_{i t}\right)$ is simply given by $A_{i t} \cdot K_{i t}$. At the industry level, total supply $Q_{t}$ corresponds to the sum of individual outputs. The price is given by the following unit-elastic demand function:

$$
\mathrm{P}_{\mathrm{t}}\left(\mathrm{Q}_{\mathrm{t}}\right)=\frac{\mathrm{D}}{\mathrm{Q}_{\mathrm{t}}} \text { with } \mathrm{D}>0
$$


We assume that the variable production cost per unit capital ( $\partial$ is constant over firms and technologies so that the profit 3 of firm $i$ at time $t$ is given by $\Pi_{i t}=\left(P_{t} \cdot A_{i t}-c\right) \cdot K_{i t}$. For each firm, we denote $\pi_{i t}$ the profit rate per unit capital.

At each period firms invest in R\&D and in capital in order to expand their market shares. We assume that R\&D is a priority for firms since their survival in the industry mainly depends on their ability to increase their productivity level. Nevertheless firms first cover the physical depreciation of their capital stock. Thus the sequence of investment decisions is the following: first compensating for the physical depreciation of capital, then investment in R\&D, and finally additional capital investment in order to increase the capital stock. This sequence is justified by the fact that, although $R \& D$ is a priority, firms are not willing to endure decreases in their capital stock insofar as it leads to decreases in their productive capacity.

\section{- Innovative strategy of firms}

We assume that decision rules governing firms' investments are simple fixed rules which reflect bounded rationality. The rules of $R \& D$ investment are differentiated among firms since they exhibit different innovative strategies. We propose to distinguish between two types of firms according to their learning process and innovative strategy. We consider two types of firms: amlativefirms and nonamulative ones. This distinction refers to the argument of Malerba (1992) according to which firms learn in a variety of different ways, mainly because each firm accumulates its own technological knowledge base according to its experiences and competencies. Moreover learning is linked to different sources of knowledge that may be either internal or external to the firm. We propose to use this distinction between internal and external learning in order to characterise the innovative strategy of firms.

Malerba (1992) defines internal learning to be "leamingby seardingintemal to thefimmandmainly reated to fomalised adivities, such as R\&D, aimed at geneatingnewknoweelge'. In our model, the firms that adopt an innovative strategy based on this type of learning are called cumulative firms, in reference to the internal process of knowledge accumulation. In contrast, the learning process is external when it deals with knowledge coming from external sources, such as public research and industry spillovers. Malerba (1992) calls this second type of learning "leaming fromadvanes in science and techndogy and leaming from industry spillowers". We call non-cumulative firms the firms that adopt an innovative strategy based on external learning.

The distinction between internal and external learning is restrictive since no learning process is exclusively internal or external. Even if a firm does not collect external knowledge voluntarily, its research activities always involve, to a certain extent, knowledge that has not been developed internally. In the same way, purely external learning does not exist since the ability of firms to absorb and to exploit external knowledge depends on their internal stock of knowledge and competencies. Nevertheless the interest of this typology is to emphasise different learning mechanisms. Implicitly it is also related to the usual distinction between innovation and imitation. But the reference to learning process provides a more precise analysis of the process of knowledge accumulation which guides innovative and imitative activities of firms. It seems to us that the basic distinction between innovation and imitation is generally associated with a too exclusive and systematic representation of research activities of firms. It is the reason why in our model, we differentiate firms according to the typology of learning processes, which enables us to take into account the role of the absorptive capacity of firms.

\footnotetext{
${ }^{3} \Pi_{i t}$ is the gross profit before investment.
} 


\section{- Innovative strategy of cumulative firms}

Cumulative firms correspond to the category of firms which invest in R\&D in order to accumulate technological knowledge and to generate innovation internally. According to Malerba's taxonomy (1992), we can say that these firms adopt a leaming by serchingprocess that is internal to the firm and mainly related to R\&D activities aiming at developing and accumulating new technological knowledge.

\section{- R\&D investment}

We assume that cumulative firms invest in R\&D in order to maintain an efficient level of technological performances. Therefore a firm's level of R\&D investment is determined by comparing the technological performances of the firm considered with the industry average level of performances. In our model technological performances are represented by productivity levels of firms. We assume that cumulative firms increase their R\&D investment when they suffer a technological lag in comparison with the market share weighted industry average productivity.

The desired investment rate in R\&D per sales unit of firm $i$ at time $t\left(r_{i t}^{\mathrm{ds}}\right)$ is determined according to the following rule :

$$
\begin{aligned}
& \text { If } \mathrm{A}_{\mathrm{it}}<\overline{\mathrm{A}}_{\mathrm{t}}, \mathrm{r}_{\mathrm{it}}^{\mathrm{dss}}=\mathrm{r}_{\mathrm{i}, \mathrm{t}-1}^{\mathrm{ds}}+\lambda \cdot\left(\overline{\mathrm{A}}_{\mathrm{t}}-\mathrm{A}_{\mathrm{it}}\right) \\
& \text { If } \mathrm{A}_{\mathrm{it}} \geq \overline{\mathrm{A}}_{\mathrm{t}}, \mathrm{r}_{\mathrm{it}}^{\mathrm{dss}}=\mathrm{r}_{\mathrm{i}, \mathrm{t}-1}^{\mathrm{ds}}
\end{aligned}
$$

with $\bar{A}_{t}$ the market share weighted industry average productivity given by $\sum_{\mathrm{i}=1}^{\mathrm{n}} \mu_{\mathrm{it}} . \mathrm{A}_{\mathrm{it}}, \mu_{\mathrm{it}}$ being the market share of firm $i$ at time $t \lambda$ is an adaptation parameter of $R \& D$ investment such as $0<\lambda<1$. According to this rule cumulative firms increase their R\&D investment proportionally to their technological lag.

Effective R\&D expenditure are bounded above by the budget constraint i.e. profit minus capital depreciation. Thus total $R \& D$ expenditure of firm $i$ at time tare given by :

$$
\mathrm{R}_{\mathrm{it}}=\operatorname{Min}\left(\mathrm{r}_{\mathrm{it}}^{\mathrm{ds}} \cdot \mathrm{P}_{\mathrm{t}} \cdot \mathrm{Q}_{\mathrm{it}} ; \Pi_{\mathrm{it}}-\delta \mathrm{K}_{\mathrm{it}}\right)
$$

with $\delta$ the depreciation rate of capital.

Firms' R\&D expenditure determine their research level $\left(\overline{\mathrm{R}}_{\mathrm{it}}\right)$ which is a weighted average of past research levels and current R\&D expenditure. This research level index describes the evolution of firms' $R \& D$ expenditure:

$$
\overline{\mathrm{R}}_{\mathrm{it}}=\alpha_{\mathrm{R}} \overline{\mathrm{R}}_{\mathrm{i}, \mathrm{t}-1}+\left(1-\alpha_{\mathrm{R}}\right) \cdot \mathrm{R}_{\mathrm{it}} \text { with } \alpha_{\mathrm{R}} \text { a parameter weighting past research levels }\left(0<\alpha_{\mathrm{R}}<1\right)
$$

R\&D activities of firms enable them to develop and to accumulate new technological knowledge. In other words, every firm builds its specific knowledge base through its research activities. Then this knowledge base determines the firms' ability to innovate.

\section{- Knoweergeacamilation andinnovation}

We model the "learning by searching" process of cumulative firms through a knowledge accumulation function depending on R\&D investment. We assume that at time the stock of accumulated knowledge of firm $i$ is given by the following equation:

$$
\mathrm{z}_{\mathrm{it}}=\left(1-\alpha_{\mathrm{z}}\right) \mathrm{z}_{\mathrm{i}, \mathrm{t}-1}+\overline{\mathrm{R}}_{\mathrm{it}}
$$

with $\alpha_{\mathrm{z}}$ the depreciation rate of knowledge and $\bar{R}_{i t}$ the research level of the firm. 
We then assume that only a part of this stock of technological knowledge is actually exploitable by firms in their innovative activities. This leads us to consider a function of exploitable technological knowledge $\left(\bar{z}_{\text {it }}\right)$ which is given by a logarithmic function of the total accumulated knowledge:

$$
\overline{\mathrm{z}}_{\mathrm{it}}=\ln \left(1+\mathrm{z}_{\mathrm{it}}\right)
$$

This function implies decreasing returns on $R \& D$ in the accumulation of exploitable technological knowledge.

The stock of exploitable knowledge determines the probability to innovate which is a logistic probability function:

$$
\mathrm{P}_{\mathrm{it}}^{\mathrm{Im}}=\frac{\mathrm{P}_{1}}{\mathrm{P}_{2}+\mathrm{P}_{3} \cdot \exp \left(-\mathrm{a}_{\mathrm{n}} \overline{\mathrm{Z}}_{\mathrm{it}}\right)}
$$

with $P_{\text {it }}^{\operatorname{Inn}}$ the probability of firm $i$ to innovate at time $t ; P_{1}, P_{2}, P_{3}$ the parameters bounding the logistic function and $a_{n}$ the speed at which the maximum probability to innovate is approached. This logistic function implies increasing and then decreasing returns in the process of innovation.

The technological trajectory of the industry is given by the techndogy space which is a set of productivity levels (see appendix) ${ }^{4}$. This technology space, which represents the potentialities of the prevailing technology, is not known by firms. Through their innovative activities firms try to progress in their exploitation of the technology potentialities. In this perspective, we assume that the innovation process consists in a draw of a productivity level in a normal distribution centred around the current productivity level of the innovative firm (with standard deviation $\sigma$ ). Then the productivity level of the new technology $\left(\mathrm{A}_{\mathrm{it}}^{\mathrm{Im}}\right.$ ) is the productivity level of the technology space that is closest to the innovative draw.

The new technology is adopted by the firm only if it provides a higher productivity level than the prevailing technology. Thus the productivity level of firm i for the next period is given by:

$$
A_{i, t+1}=\operatorname{Max}\left(A_{i t} ; A_{i t}^{I m n}\right)
$$

The assumption according to which innovative draws are centred around the current productivity level of the innovative firm reflects the amulativeness of innovation. It implies that the results of innovation are determined by past technological performances of innovative firms. It means that each firm is able to follow its own technological trajectory according to its research activities and knowledge accumulation. In that sense, the innovation process is cumulative at the firm level.

\section{- Innovative strategy of non-cumulative firms}

This second category of firms is involved in an innovation process depending on external sources of knowledge. We assume that non-cumulative firms learn from public research and intra-industry spillovers. Cohen and Levinthal $(1989,1990)$ emphasise this dimension of R\&D activities by arguing that while R\&D generates innovations, it also develops the ability of firms to exploit knowledge coming from the environment. This ability is what the authors call theabsontivecapaaty of firms: this capacity to absorb externally generated knowledge depends on $R \& D$ activities and on the characteristics of the knowledge to be absorbed. In Cohen and Levinthal (1989), these characteristics are represented by a parameter $(\beta)$ that reflects the degree of complexity and specificity of knowledge. $\beta$ is increasing with the complexity of knowledge and decreasing with the degree to which it is targeted to industrial applied developments and to the needs of firms: the higher $\beta$, the more difficult the absorption of knowledge.

\footnotetext{
${ }^{4}$ We use the concept of technology space (or search space) proposed by Andersen (1994) which enables us to localise the innovations of firms on a pre-defined technological trajectory that represents the potentialities of the prevailing technology. That way, we can compare the ability of firms to progress along this technological trajectory.
} 
Following Cohen and Levinthal, we assume that non-cumulative firms build up their absorptive capacity progressively on the basis of their R\&D activities. We consider the absorptive capacity of noncumulative firms $\left(\gamma_{i t}\right)$ to be a function of their research level ${ }^{5}$ :

$$
\gamma_{\text {it }}=1-\frac{2 \beta}{\sqrt{\overline{\mathrm{R}}_{\text {it }}}} \text { with } 0<\beta<1
$$

The research strategy of non-cumulative firms consists in investing in $R \& D$ in order to improve their absorptive capacity and to exploit technological knowledge coming from public research and intra-industry spillovers.

\section{- R\&D investment}

The motivation of non-cumulative firms to invest in R\&D is linked to their absorptive capacity. We assume that their purpose is to reach the maximum absorptive capacity in order to be able to exploit the maximum of the technological knowledge externally generated. This upper limit of the absorptive capacity function is noted $\bar{\gamma}$. The desired investment rate in R\&D per sales unit is given by:

$$
\begin{aligned}
& \text { If } \gamma_{\mathrm{it}}<\bar{\gamma}, \quad \mathrm{r}_{\mathrm{it}}^{\mathrm{des}}=\mathrm{r}_{\mathrm{i}, \mathrm{t}-1}^{\mathrm{des}}+\lambda \cdot\left(\bar{\gamma}-\gamma_{\mathrm{it}}\right) \\
& \text { If } \gamma_{\mathrm{it}} \geq \bar{\gamma}, \quad \mathrm{r}_{\mathrm{it}}^{\mathrm{des}}=\mathrm{r}_{\mathrm{i}, \mathrm{t}-1}^{\mathrm{des}}
\end{aligned}
$$

This rule reflects the fact that non-cumulative firms increase their desired investment rate in $R \& D$ proportionally to their lack of absorptive capacity. But effective $R \& D$ expenditure are bounded above by the residual profit after the covering of the physical depreciation of capital. Total R\&D expenditure of firm $i$ at time tare given by:

$$
\mathrm{R}_{\mathrm{it}}=\operatorname{Min}\left(\mathrm{r}_{\mathrm{it}}^{\mathrm{des}} \cdot \mathrm{P}_{\mathrm{t}} \cdot \mathrm{Q}_{\mathrm{it}} ; \Pi_{\mathrm{it}}-\delta \mathrm{K}_{\mathrm{it}}\right)
$$

This R\&D investment determines the research level of non-cumulative firms ( $\left.\bar{R}_{i t}\right)$ according to the same equation as the one used for cumulative firms.

\section{- Knowteedgeacamlation andinnovation}

Non-cumulative firms accumulate technological knowledge by absorbing knowledge resulting from intra-industry spillovers and public research. We assume that the level of spillovers depends on the market share weighted average research level $\left(\bar{R}_{t}\right)$ which is given by:

$$
\overline{\mathrm{R}}_{\mathrm{t}}=\sum_{\mathrm{i}=1}^{\mathrm{n}} \mu_{\mathrm{it}} \overline{\mathrm{R}}_{\mathrm{it}} \text { with } \mu_{\mathrm{it}}=\frac{\mathrm{Q}_{\mathrm{it}}}{\sum_{\mathrm{i}=1}^{\mathrm{n}} \mathrm{Q}_{\mathrm{it}}}
$$

$\mu_{\text {it }}$ is the market share of firm $i$ at time $t$

We assume that the largest firms (in terms of market shares) generate more spillovers than the smallest ones ${ }^{6}$. That is the reason why we assume that the level of spillovers is given by the rate of spillovers $\left(\theta_{\mathrm{s}}\right)$ multiplied by the market share weighted average research level $\left(\overline{\mathrm{R}}_{\mathrm{t}}\right)$.

Thus the stock of exploitable technological knowledge of firm i at time tis given by:

\footnotetext{
${ }^{5} \mathrm{As}$ in Cohen and Levinthal (1989), the absorptive capacity function is increasing at a decreasing rate with firms $\mathrm{R} \& \mathrm{D}$ investment, decreasing with $\beta$ and so that the marginal impact of own $R \& D$ on absorptive capacity is increasing with $\beta$. ${ }^{6}$ This assumption is linked to the argument according to which the growth of firms is one of the mechanisms by which the use of a profitable new technology is spread (Nelson, 1996).
} 


$$
\overline{\mathrm{z}}_{\mathrm{it}}=\left(1-\alpha_{\mathrm{z}}\right) \cdot \overline{\mathrm{z}}_{\mathrm{i}, \mathrm{t}-1}+\gamma_{\mathrm{it}} \cdot\left[\theta_{\mathrm{s}} \cdot \overline{\mathrm{R}}_{\mathrm{t}}+\mathrm{R}_{\mathrm{p}}\right]
$$

with $\alpha_{z}$ the depreciation rate of knowledge and $R_{p}$ the level of public research exploitable by firms. According to this equation, the stock of exploitable technological knowledge of non-cumulative firms is composed of the knowledge previously accumulated and the absorbed external knowledge. This external knowledge is given by the level of intra-industry spillovers and the public research which is relevant for firms and exploitable within the considered industry.

The stock of exploitable knowledge determines the probability to innovate according to the same logistic probability function as the one of cumulative firms. The innovation process also consists in a draw of a productivity level in a normal distribution. The distinctive feature of the innovation process of non-cumulative firms is that innovative draws are centred around the market share weighted industry average productivity $\left(\overline{\mathrm{A}}_{t}\right)$. This feature implies that non-cumulative firms do not follow their own technological trajectory but the one of the industry. We call these firms non-cumulative since they do not accumulate knowledge generated internally, but exploit external sources of knowledge and try to absorb technological advances of the industry. The purpose of non-cumulative firms is mainly to follow the technological trend of the industry. In that sense, the innovation process is not cumulative at the level of firms but at the level of the whole industry. The innovative strategy of these firms is closer to a specific type of technology imitation than to a purely innovative strategy. But this strategy does not exhibit the systematic character of imitation which is generally modelled so that imitative firms can imitate the technology of a competing firm directly and totally. The modelling of the innovative strategy of non-cumulative firms takes into account the role of the absorptive capacity and their different ability to follow the technological trend of the industry.

\section{- Capital investment}

After having invested in $R \& D$, firms determine whether they increase their capital stock or not. We do not consider any differentiation between the two types of firms and we assume that they use the same simple satisficing rule to set the level of their additional investment in capital. The return on investment per capital unit is given by the profit rate $\pi_{i t}$. Let $\rho$ denote the minimum expected rate of return on capital. If the rate of return $\pi_{i t}$ is smaller than this minimum rate, firms do not make any additional investment, that is they do not invest more than the physical depreciation of their capital stock. In the opposite case, firms invest part of their profits to increase their capital stock. In that case, the desired rate of capital growth $(\tau)$ is constant and equal for each firm. Let $\Delta \mathrm{K}_{\mathrm{it}}$ denote the additional capital investment of firm $\mathrm{i}$ at time tin capital units (the unit price of capital being equal to 1). Given that there is no external financing, additional capital investment is bounded above by residual profits after the covering of physical depreciation and $R \& D$ investment. Thus the decision rule governing additional capital investment is given by:

$$
\begin{array}{ll}
\text { If } \pi_{\mathrm{it}}<\rho & \Delta \mathrm{K}_{\mathrm{it}}=0 \\
\text { If } \pi_{\mathrm{it}} \geq \rho & \Delta \mathrm{K}_{\mathrm{it}}=\operatorname{Min}\left[\tau . \mathrm{K}_{\mathrm{it}} ;\left(\Pi_{\mathrm{it}}-\delta \mathrm{K}_{\mathrm{it}}-\mathrm{R}_{\mathrm{it}}\right)\right]
\end{array}
$$

with $\delta$ the depreciation rate of capital.

\section{- Entry and exit of fims}

The entry and exit process is endogenous to the model et is based on an index of firms' performances. We assume that each firm is characterised by a performance index $\left(\mathrm{X}_{\mathrm{it}}^{\mathrm{P}}\right)$ which depends on its profit rate:

$$
\left.\mathrm{X}_{\mathrm{it}}^{\mathrm{P}}=\alpha_{\mathrm{P}} \cdot \mathrm{X}_{\mathrm{i}, \mathrm{t}-1}^{\mathrm{P}}+\left(1-\alpha_{\mathrm{P}}\right) \pi_{\mathrm{it}} \quad \text { with } \alpha_{\mathrm{P}} \in\right] 0,[\mathrm{l} \text { a parameter weighting past performance }
$$


A firm may exit the industry for either of two reasons. The first reason is the decrease of the capital stock below a minimum level $\mathrm{K}_{\mathrm{Min}}$. The second condition for exit is that the performance level of the firm is below a critical negative level $\mathrm{X}_{\mathrm{Min}}$.

As to entry of firms, we differentiate between two types of entrants, that is between cumulative and non-cumulative firms. For each type of entrants, the entry process is a Poisson process with means $\mathrm{N}^{\mathrm{C}}$ and $\mathrm{N}^{\mathrm{NC}}$ corresponding respectively to the average number of potential cumulative and noncumulative entrants.

We assume that amulative firms enter the industry endowed with a technology resulting from innovation. More precisely they draw a productivity level in a normal distribution centred around the market share weighted industry average productivity. Then they adopt the technology $\left(\mathrm{A}^{\mathrm{C}}\right)$ which corresponds to the productivity level of the technology space that is the closest to this innovative draw. Concerning non-cumulative firms, we assume that they enter the industry by imitating the technology of the biggest firm of the industry (in terms of market share). This assumption is linked to the fact that the spillovers generated by a firm increase with its market share. In other words, the technology of the biggest firm is the most "visible" technology and hence the one that is imitated by non-cumulative entrants.

Let $\left(\mathrm{A}^{\mathrm{NC}}\right)$ denote the productivity level of non-cumulative potential entrants. Whether a potential entrant becomes an actual entrant depends on the evaluation of the profit opportunities generated by the technology at the time of entry. This evaluation consists in multiplying the productivity level of entrants $\left(A^{N C}\right.$ or $\left.A^{C}\right)$ by the current price of output $\left(P_{t}\right)$ and subtracting from the result the cost of production per capital unit (c). This calculation determines the net rate of excess return per period which must be superior to the entry barrier rate $\left(r_{e}\right)$ for the potential entrant to become an actual entrant.

\section{The impact of diversity upon industrial dynamics: results of the simulations}

In order to study the role of the diversity of innovative strategies, we compare three configurations:

- the first one corresponds to the non-cumulative case in which every firm adopts the noncumulative innovative strategy;

- the second configuration corresponds to the pure cumulative case - i.e. only cumulative firms enter the industry -;

- in the third configuration, which corresponds to the diversity case, the mean of the Poisson entry process for cumulative and non-cumulative firms is calibrated so that the number of effective entrants of each type is approximately the same.

By comparing these configurations, we explore the impact of the co-existence of the two types of firms upon the industrial dynamics.

Given that the industrial dynamics is mainly driven by stochastic innovative draws, we run 100 simulations for each configuration, each simulation being 500 iterations long. The purpose is to generate enough histories to be able to tackle the emergent properties of the industrial dynamics and in particular to infer properties relatively independent of the sequences of random numbers. The values of the parameters used in the simulations are presented in appendix. In a first step we present the average results (and standard deviation) of these 100 simulation runs. Then for the most relevant variables, such as productivities and market shares, we use the whole distribution generated by the simulations. 


\subsection{The evolution of market structure}

The following table presents the average final period results of 100 simulation runs for each configuration. The numbers in parentheses correspond to the standard deviations of the 100-run samples. To characterise the evolution of the industrial structure, we use the Herfindahl numbers equivalent index $\left(1 / \mathrm{H}_{\mathrm{t}}\right)$ :

$$
\frac{1}{\mathrm{H}_{\mathrm{t}}}=\frac{1}{\sum_{\mathrm{i}=1}^{\mathrm{n}} \mu_{\mathrm{it}}^{2}}
$$

where $n_{t}$ is the number of firms in the industry at period tand $\mu_{i t}$ is the market share of firm $i$ at time $\mathrm{t}$

In table 1, C-firms denotes cumulative firms and NC-firms non-cumulative ones. For each type, we distinguish the number of entrants from the number of firms surviving in the industry in the long run.

\begin{tabular}{lccc}
\hline & Non-Cumulative Case & Cumulative Case & Diversity Case \\
\hline Herfindahl numbers equivalent & $11.7(2.2)$ & $1.9(0.7)$ & $5.5(1.9)$ \\
Capital stock per firm & $191.8(41.7)$ & $1105(362)$ & $296(71)$ \\
R\&D expenditure per firm & $3.28(0.9)$ & $11.9(7.7)$ & $4.7(2.1)$ \\
\hline Nb. of C-entrants & - & $14(2.5)$ & $7.6(2.2)$ \\
Nb. of NC- entrants & $14.2(3)$ & - & $7.8(2.5)$ \\
Nb. of surviving C-firms & - & $2.6(1)$ & $1.6(0.8)$ \\
Nb. of surviving NC-firms & $13.8(3)$ & - & $7.5(2.2)$ \\
\hline Average productivity level & $1.96(0.27)$ & $2.13(0.35)$ & $2.2(0.29)$ \\
Average maximum productivity & $2.02(0.27)$ & $2.36(0.26)$ & $2.29(0.25)$ \\
\hline
\end{tabular}

Table 1: Average final period results of each configuration

We notice a significant difference in concentration between the three configurations. On average the cumulative case is concentrated as if it was composed of two firms of equal size. Over 100 simulation runs, we observe 56 cases of duopoly in the long run. We also observe that the number of cumulative entrants surviving in the long run is very low: on average almost 14 cumulative firms enter the industry, but only 2.6 survive. This feature characterises the trend towards concentration of the cumulative configuration. This trend is also illustrated by the distribution of the final period market share of firms (figure 1 in appendix) 7 . The median of this distribution is equal to 0.32 which means that $50 \%$ of the firms reach a market share superior to $32 \%$. The high market shares of firms explain the intensity in capital and in R\&D of the cumulative configuration. Indeed we observe that the average capital stock and R\&D expenditure per firm are markedly higher than in both other configurations. This result is linked to a self-enforcing effect between concentration and intensity in capital and in R\&D, which is one of the characteristics of cumulative technological regimes (Oltra, 1997a). In terms of diversity, we

\footnotetext{
${ }^{7}$ More precisely, figure 1 represents the distribution of the final period market share attained by firms in each simulation run (over the 100-runs samples).
} 
also have to stress that the distribution of final period market shares exhibits a wide dispersion which is due to cumulativeness.

As to the non-cumulative case, it exhibits the opposite properties that is a low degree of concentration, a high rate of survival of NC-entrants (almost equal to 1) and a low intensity in capital and in $R \& D$. The distribution of the final period market share of firms (figure 2 in appendix) points out that the market is equitably shared among firms which have a final period market share contained between $5 \%$ and $15 \%$ (with a mode equal to 10\%). We can argue that the non-cumulative case is not associated with a diversity of firms' market share.

The diversity case exhibits an intermediate value of the Herfindahl numbers equivalent which is equal to 5.5 (on average). We can say that, in terms of concentration, the diversity case corresponds to an intermediate configuration in comparison with both other cases. We can notice that almost all the NC-entrants survive in the long run, while the rate of survival of C-firms is only equal to $15 \%$. Thus the diversity case ends up in an oligopolistic structure composed of a few cumulative firms and of almost all the non-cumulative entrants. Figure 3 in appendix shows that, in the long run, C-firms dominate the industry with high market shares, while NC-firms survive with lower market shares.

These results can be summarised by the following propositions:

Proposition 1: Theevdution of theindustrial structure is conditioned by theinnovativestrategy of fims Thepurdy amilative case leads to a highly concentrated marke structure very intensive in capital and in R\&D, whilethenonamlativecasegenerates a mudhless concentrated and morehomogeneus industrial structure

Proposition 2: Thecoexistence of both types of fims (divesity case) leads toan diggpdisticstructure haradeised by a fewC-fims (thecore) and a high rate of survival of NC-entrants (thefinge). Thereis a strong comdation between the size of fims and their inmovative strategy, since amilative fims exhibit very high and heterogeneus market shares, wheæas non-aumulativefims are haradeised by homogeneus andlowmarke shares

In order to characterise the industrial structure of the diversity case more precisely, we have to distinguish between $\mathrm{C}$-firms and $\mathrm{NC}$-firms. Figures 3 and 4 in appendix present the distribution of the final period market shares and capital stocks of $\mathrm{C}$-firms and $\mathrm{NC}$-firms in the diversity case. We observe strong similarities between these distributions. Indeed the form of the distribution of final period market shares is very similar to the one of the distribution of capital stocks for each type of firms. It is interesting to stress the wide dispersion of firms' capital stock, in particular between C-firms and NCfirms. This feature points out a diversity in capital stocks while the investment rule in capital is the same for every firm. This diversity results from the differences in firms' productivity and profit which determine the ability of firms to expand their capital stock. Thus we argue that the diversity of capital stocks is all the more linked to innovative strategy of firms since the level of capital stock corresponds to the spread of use of technology. Figure 5 in appendix shows a strong linear correlation between this diversity of capital stocks and market shares of firms.

These arguments are summarised by the following proposition:

Proposition 3: Thediversity of innovativestrategy of fims a ates a divesity of capital stoks which appears to bethe main deteminingfactor of fims marke share

These results illustrate the argument according to which diversity drives evolution and evolution generates diversity (Cohendet and Llerena, 1997). In our framework, the diversity of innovative strategies influences the industrial dynamics by creating asymmetries in the productive capacity and in the market share of firms.

\subsection{Technological performances}

In our model, technological performances correspond to the ability of firms to exploit the potentialities of the prevailing technology (given by the technology space). Thus we can evaluate these performances by the productivity level of firms. The average results presented in table 1 enable us to compare the 
industry average and maximum productivity levels that are reached in the long run in each configuration. We observe that the NC-case exhibits lower average and maximum productivity levels than both other configurations. We deduce from these results that, in the NC-configuration, firms exploit less efficiently the technology space.

In order to compare the cumulative case with the diversity one, we need to consider the whole distribution of the final period productivity level of firms since the difference is not significant on average. More precisely, for each configuration we consider the distribution of the final period productivity levels reached by firms in all the 100 simulation runs. Table 2 presents the main statistics of the distribution of each configuration.

\begin{tabular}{lcc}
\hline & Diversity case & Cumulative case \\
\hline Mean & $\mathbf{2 . 2}$ & $\mathbf{2 . 1 3}$ \\
Standard deviation & 0.29 & 0.35 \\
Variance & 0.08 & 0.12 \\
\hline First quartile & $\mathbf{2 . 0 1}$ & $\mathbf{1 . 8 6 5}$ \\
Median & $\mathbf{2 . 1 8 5}$ & $\mathbf{2 . 1 4}$ \\
Third quartile & $\mathbf{2 . 4 4}$ & $\mathbf{2 . 4 4}$ \\
\hline Mode & $\mathbf{2 . 5}$ & $\mathbf{1 . 4 2 5}$ \\
Minimum value & 1.425 & 1.3 \\
Maximum value & 2.77 & 2.8 \\
\hline
\end{tabular}

Table 2: Statistics of the distribution of the final productivities of firms (100 simulation runs)

These results show that the distribution of the final period productivity levels of firms tends to be concentrated on higher productivity values in the diversity case than in the cumulative one. We notice that the median and the mode are significantly higher in the diversity case than in the cumulative one. We conclude that firms better exploit the technology space in the diversity case than in the purely cumulative one. This argument is strengthened by the average R\&D expenditure per firm which are lower in the diversity case (cf. table 1). This feature underscores that R\&D activities are more efficient when both types of firms co-exist, since firms reach higher productivity levels with lower R\&D expenditure.

These results suggest our last proposition.

Proposition 4: The divesity of innovative strategjes of fims tends to further the techndogical evdution of the industry. In that sense, divesity of innovativestrategjes appers as a sarce of techndogical peformances

In order to describe the diversity case more precisely, we have to consider separately the productivity levels of C-firms and NC-firms. Table 3 gives us the main statistics of the distribution of the final period productivity of $\mathrm{C}$-firms and $\mathrm{NC}$-firms in the diversity case.

\begin{tabular}{lcc}
\hline & Non-Cumulative firms & Cumulative firms \\
\hline Mean & 2.22 & 2.13 \\
Standard deviation & 0.28 & 0.33 \\
First quartile & 2.02 & 1.95 \\
Median & 2.185 & 2.12 \\
Third quartile & 2.47 & 2.38 \\
Mode & 2.5 & 1.825 \\
\hline Average R\&D investment & 3.5 & 10.5 \\
\hline
\end{tabular}

Table 3: Statistics of the distribution of the final period productivity levels of firms (diversity case)

These results show that NC-firms tend to exhibit higher productivity levels than C-firms. Figure 6 in appendix represents the whole distribution of the final period productivity of both types of firms. 
We observe that the distribution of the productivity of C-firms is characterised by a wider dispersion. This is mainly due to the cumulativeness of innovation: a cumulative firm with low technological performances tends to lag behind in the industry since its innovative draws are centred around its own productivity level. It is the reason why we observe some cumulative firms with very low productivity, while others exhibit very high level of productivity.

We also check which type of firms is endowed at final period with the highest productivity level: we observe that in $50 \%$ of the cases, it is a cumulative firm which exhibits the highest productivity, while in the other simulations it is a non-cumulative firm. We can conclude that, in the long run, the diversity case tends towards an industrial structure characterised by one or two surviving cumulative firms, very intensive in capital and in $R \& D$, and a fringe of small non-cumulative firms that exhibit high technological performances resulting from the exploitation of intra-industry technological spillovers. Insofar as the surviving cumulative firms have high market shares, they generate high spillovers and their productivity levels strongly influence the innovative draws of non-cumulative firms. This dynamics reminds us the one of the pharmaceutical industry characterised by a core of innovating firms and a fringe of imitative firms (cf. section 1).

Finally, we can argue that the exploitation of technological interdependencies between both types of firms leads to an industrial structure which exploits efficiently the technology space. This result is very close to the one of Chiaromonte and D osi (1992) or Ballot and Taymaz (1997) according to which the diversity of innovative strategies is a favourable condition of technological change.

\section{Conclusion}

This paper explores the impact of the diversity of innovative strategies upon the industrial dynamics through a micro-simulation model. We consider two types of firms each one being characterised by a specific innovative strategy. Basically we assume that C-firms adopt an internal learning by searching strategy, while NC-firms adopt an external learning strategy aiming at absorbing external sources of knowledge.

The results show that the co-existence of these two types of firms leads to an oligopolistic structure characterised by asymmetries in the size of firms and high technological performances. Thus diversity appears to be both a result of the industrial dynamics, in particular in terms of capital stocks and market shares, and a condition for the innovation process since the diversity of innovative strategies tends to increase the technological performances of the whole industry. In that sense, the simulations illustrate the argument according to which diversity is a necessary condition and a result of technological change.

Finally these results suggest that an increase in the diversity of innovative strategies of firms may lead to an increase in the efficiency of the industrial dynamics. In this context there is room for policy tools appropriated for enhancing diversity as well as the exploitation of technological spillovers within industry. 


\section{References}

AND ERSEN E.S., 1994, Evdutionary economics post Shumpteian contribution", Pinter Publishers.

BALLOT G. and TAYMAZ E., 1997, "Technological change, rule generation by firms and macroeconomic coordination: an evolutionary model", Jamal of Artifical Soieies and Soial Simlation, Vol. 2, Issue 2, march 1999.

BOTTAZZI G., DOSI G., LIPPI M., PAMMOLLI F., RICCABONI M. (2000), "Processes of corporate growth in the evolution of an innovation-driven industry: the case of pharmaceuticals", mimeo, 23 February 2000, Sant'Anna School of Advanced Studies, Pisa, Italy.

CHIAROMONTE F. and DOSI G., 1992, "The micro-foundations of competitiveness and their macroeconomic applications", in FREEMAN C. and FORAY D. (eds.), Tehmology and the wealth of nations Pinter: London, pp. 107-134.

COHEN W.M., 1995, "Empirical studies of innovative activity", in STONEMAN P. (ed.), Handbodk of theeconomics of inmoation and teehndogical dange, Blackwell, pp. 182-265.

COHEN W.M. and LEVINTHAL D., 1989, "Innovation and learning: the two faces of R\&D", The EconamicJaumal, Vol.99, pp. 569-596.

COHEN W.M. and LEVINTHAL D., 1990, "Absorptive capacity: a new perspective on learning and innovation", AdministrativeSaieneQuartely, Vol. 35, pp. 128-152.

COHEN W.M. and LEVIN R.C., 1989, "Empirical studies of innovation and market structure", in SCHMALENSEE R. and WILLIG R.D. (eds.), Handbook of industrial arganization, Vol.2, Amsterdam: Elsevier, pp. 1059-1107.

COHENDET P. and LLERENA P., 1997, "Learning, technical change and public policy: how to create and exploit diversity", in EDQUIST C. (ed.), Systens of innovation: techndoges institutions and arganisations, Cassel Pinter, Chap.10, pp.223-241.

DOSI G., 1988a, "Sources, procedures and microeconomic effects of innovation", Jaumal of Econmic Litterature, Vol. XXVI, pp. 1120-1171.

DOSI G., 1988b, "The nature of the innovative process", in DOSI et al., 1988, Tednical dangeand economic theary, Pinter Publishers Ltd.

DOSI G., MALERBA F., MARSILI O. and ORSENIG O L., 1997, "Industry structures and dynamics: evidence, interpretations and puzzles", Industrial and CoporateChange, Vol. 6, pp. 1-24.

GRABOWSKI H. and VERNON J., 1987, "Pioneers, imitators and generics. A simulation model of Schumpeterian competition", Q uarterly Journal of Economics, Vol. 102, pp.491-525.

IWAI K., 1984, "Schumpeterian dynamics I and II", Jaumal of EconmicBehaviaur and Organization, Vol.5, pp. 159-190, 321-351.

JONARD N. and YILDIZOGLU M., 1998, "Technological diversity in an evolutionary model with localized learning and network externalities", Structural ChangeandEconomicDynamics, Vol.9, pp.35-55. 
LLERENA P. and OLTRA V., 1998, "The role of diversity in industrial dynamics", Paper presented at the International J.A. Schumpeter Society, Vienna, Austria, 13-16 June 1998.

MALERBA F., 1992, "Learning by firms and incremental technical change", TheEconamicJaumal, Vol. 102, pp. 845-859.

MALERBA F. and ORSENIGO L., 1996, "Schumpeterian patterns of innovation are technology specific", RearchPdig, Vol. 25, pp. 451-478.

MALERBA F. and ORSENIGO L., 1997, "Technological regimes and sectoral patterns of innovation activities", Industrial and ComparateChange, Vol. 6, pp. 83-117.

METCALFE S., 1992, "Variety, structure and change: an evolutionary perspective on the competitive process", RevuedEconmieIndustrielle, Special Issue, Tehndogical divesity and cherencein Europe, Vol.59, pp. 46-61.

NELSO N R.R. and WINTER S.G., 1982, An eddutionary theery of econamic dhange, Boston, Mass., The Belknap Press of Harvard University Press.

NELSO N R.R., 1996, Thesaurces of economicgonth, Harvard University Press.

NELSON R.R., 1994, "The co-evolution of technology, industrial structure and supporting institutions", Industrial and ConparateChange, V ol. 3, pp. 47-63.

OLTRA (1997a), Industrial Dynamics and diversity in schumpteian tehndogical regimes Strasbourg: Mimeo BETA n 9715.

O LTRA (1997b), Pditiques techndogiques \& dynamiqueindustrielle, Thèse de D octorat de l'Université Louis Pasteur, Strasbourg.

PATEL P. and PAVITT K., 1995, "Patterns of technological activity: their measurement and interpretation", in STONEMAN P. (ed.), Handbook of the economics of innovation and techndogical dhange, Blackwell, pp. 14-52.

SAVIOTTI P.P., 1991, "The role of variety in economics and technological development", in SAVIOTTI P.P. and METCALFE S. (eds.), Evdutionary theories of economic and teehnical donge present statusandfutureprospets, Chur (GBR): Harwood Academic Publishers, pp. 172-208.

SILVERBERG G., DOSI G. and ORSENIGO L., 1988, "Innovation, diversity and diffusion: a selforganization model", TheEconamicJaumal, Vol.98, pp. 1032-1054. 


\section{Appendix}

\section{- Parameter settings}

Parameter in the demand function: $\mathrm{D}=500$

Production cost per unit capital: $\mathrm{c}=0.16$

D epreciation rate of capital: $\delta=0.02$

Expected return rate of capital: $\rho=0.05$

Increase rate of capital: $\tau=0.05$

Parameters weighting past performances: $\alpha_{R}=\alpha_{P}=0.5$

Adaptation coefficient in R\&D investment rate: $\lambda=0.1$

D egree of complexity of knowledge: $\beta=0.3$

Depreciation rate of knowledge: $\alpha_{z}=0.3$

Spillovers rate: $\theta_{s}=0.03$

Public research level: $R_{P}=0.3$

Upper limit of the absorptive capacity: $\bar{\gamma}=0.8$

Parameters in the logistic function of probability to innovate:

$\mathrm{P}_{1}=0.035, \mathrm{P}_{2}=0.05, \mathrm{P}_{3}=0.65, \mathrm{a}_{\mathrm{n}}=4.5$

Standard deviation of innovative draws: $\sigma=0.025$

Means of the entry Poisson process:

- cumulative case $\mathrm{N}^{\mathrm{C}}=0.35$

- non-cumulative case $\mathrm{N}^{\mathrm{NC}}=0.25$

- diversity case $\mathrm{N}^{\mathrm{C}}=0.2$ and $\mathrm{N}^{\mathrm{NC}}=0.05$

Entry barrier rate: $r_{e}=0.05$

Minimum performance level: $X_{\text {Min }}^{P}=-0.05$

Minimum capital stock level: $K_{\text {Min }}=20$

Initial $R \& D$ desired investment rate: $\mathrm{r}^{\mathrm{ds}}=0.05$

- Technology space (productivity levels):

$\{0.4,0.41,0.42,0.43,0.435,0.44,0.45,0.46,0.48,0.5,0.506,0.51,0.515,0.52,0.53,0.54,0.55,0.56,0.58$, $0.60,0.64,0.67,0.7,0.705,0.71,0.715,0.72,0.726,0.730,0.74,0.745,0.75,0.76,0.77,0.80,0.81,0.815$, $0.82,0.83,0.838,0.842,0.85,0.86,0.87,0.875,0.88,0.888,0.9,0.92,0.95,0.97,1.01,1.05,1.08,1.10,1.105$, $1.110,1.115,1.120,1.130,1.14,1.15,1.158,1.166,1.176,1.186,1.201,1.211,1.22,1.23,1.245,1.263,1.283$, $1.303,1.33,1.36,1.39,1.425,1.475,1.5,1.51,1.515,1.52,1.53,1.538,1.545,1.55,1.576,1.604,1.614$, $1.619,1.629,1.644,1.659,1.677,1.69,1.705,1.723,1.74,1.755,1.775,1.795,1.825,1.865,1.895,1.925$, $1.95,1.975,2.0,2.01,2.02,2.03,2.035,2.04,2.05,2.072,2.087,2.105,2.12,2.14,2.16,2.185,2.20,2.22$, $2.23,2.24,2.255,2.26,2.27,2.275,2.28,2.29,2.298,2.313,2.33,2.347,2.36,2.378,2.396,2.416,2.44,2.47$, $2.5,2.53,2.56,2.58,2.6,2.63,2.65,2.67,2.69,2.7,2.73,2.75,2.77,2.80,2.82,2.84,2.87,2.9,2.95,3.0\}$ 


\section{- Results of the simulations}
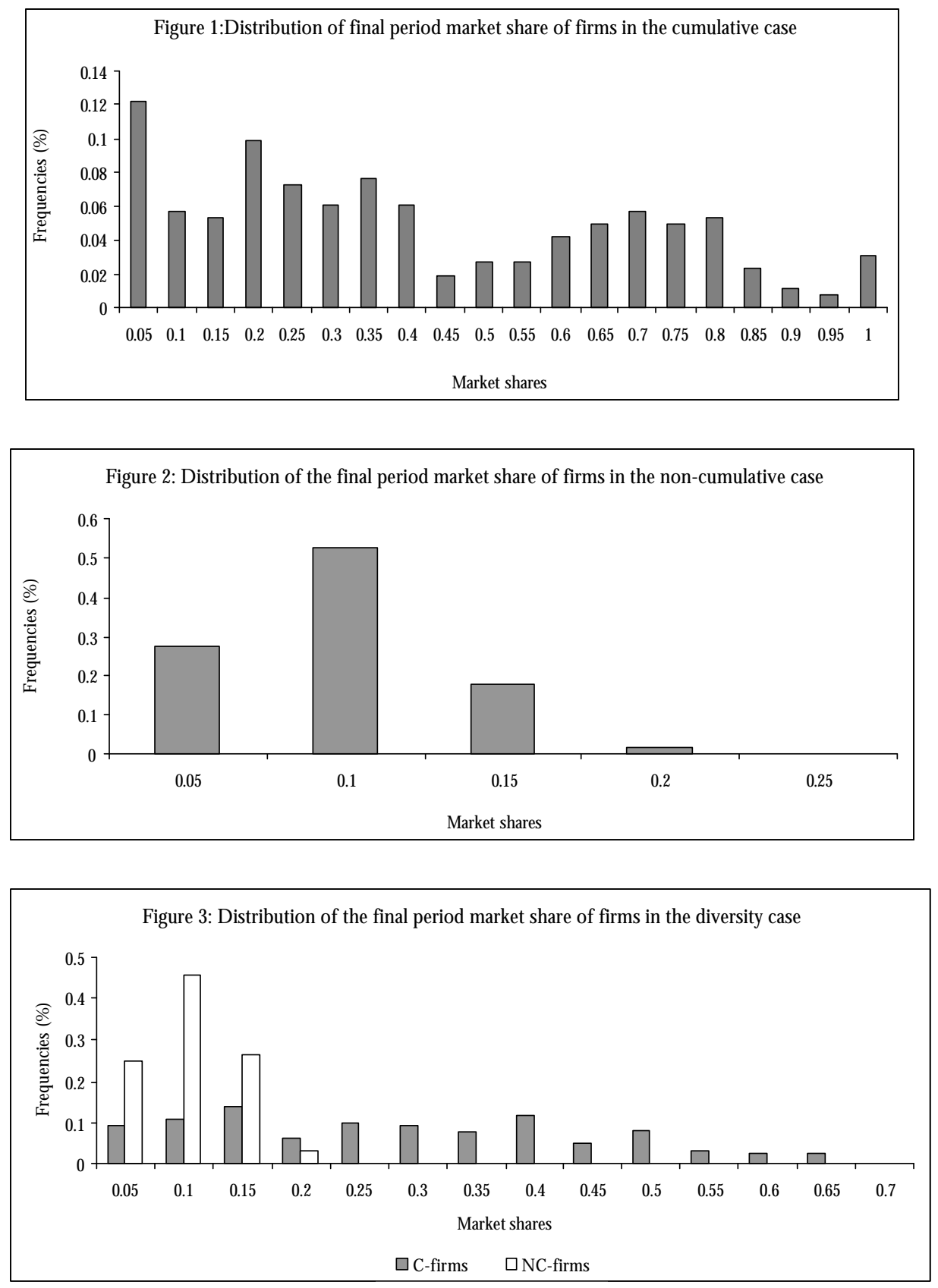

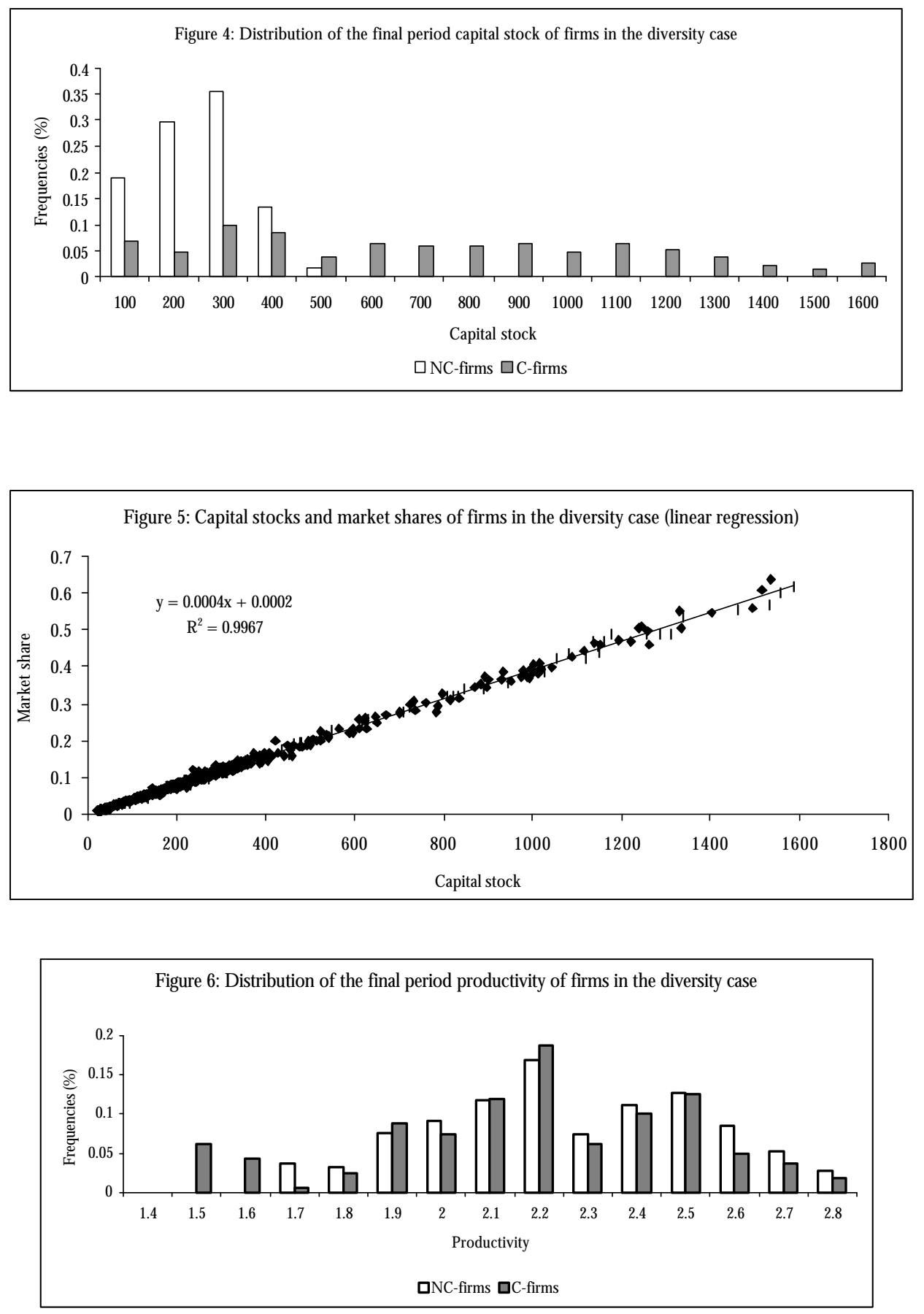